\title{
Panorama sobre Currículo em Educação Matemática
}

\section{Wagner Barbosa de Lima Palanch}

Secretaria Municipal de Educação de São Paulo

wagnerpalanch@uol.com.br

\begin{abstract}
Resumo
Este artigo apresenta um panorama sobre currículo em Educação Matemática. Para isso, por meio do contexto histórico, mostro a reorganização curricular em diferentes momentos. Em seguida, exploro conceitos sobre currículo, desenvolvimento curricular, processos de implementação do currículo e relações entre currículo, cultura, diversidade e Educação Matemática. Essas discussões estão situadas nos estudos do campo da Educação e da Educação Matemática, as quais apontam que outras perspectivas ganharam espaço na reorganização curricular: interdisciplinaridade, temas geradores, projetos, entre outros. Essas perspectivas possibilitaram avanços nas discussões sobre os processos de ensino e de aprendizagem da Matemática.
\end{abstract}

Palavras-chave: Educação Matemática. Currículo. Reorganização Curricular.

\section{Overview of Curriculum in Mathematics Education}

\begin{abstract}
This paper provides an overview of the curriculum in mathematics education. For this, through the historical context, show the curricular reorganization at different times. Then explore concepts of curriculum, curriculum development, curriculum implementation processes, and relationships between curriculum, culture, diversity and mathematics education. These discussions are situated in the field of studies of Education and Mathematics Education, which show that other perspectives gained space in the curriculum reorganization: interdisciplinarity, generative themes, among others. These perspectives have enabled advances in the discussions on the processes of teaching and learning of mathematics.
\end{abstract}

Keywords: Mathematics Education. Curriculum. Curricular Reorganization.

\section{Contexto histórico}

Desde o início do século XX, há debates que envolvem os estudos curriculares. Os acontecimentos sociais, culturais, econômicos e políticos impactam de forma decisiva as práticas educacionais e curriculares. O processo histórico evidencia revisões periódicas no campo curricular por decorrência de pressões institucionais e forças sociais. Currículo é um processo que envolve 
saberes, cultura, conhecimentos escolares e toda relação que existe dentro da escola entre seus agentes. O currículo, como construção cultural, é uma prática complexa que pode apresentar diversas perspectivas e muitas significações. Mais ainda, precisa ser visto não como algo posto e imutável, mas, como sugere Sacristán (2000, p. 15), é “'[...] a concretização das funções da própria escola e a forma particular de enfocá-las num momento histórico e social determinado".

Doll (1997, p. 178), ao discorrer sobre o conceito de currículo, traz a noção de matriz de currículo para elucidar sua natureza não linear, mas construtiva.

[...] Um currículo construtivo é aquele que emerge através da ação e interação dos participantes; ele não é estabelecido antecipadamente (a não ser em termos amplos e gerais). Uma matriz, evidentemente, não tem início nem fim; ela tem fronteiras e pontos de interseção ou focos. Assim, um currículo modelado em uma matriz também é não-linear e não-sequencial, mas limitado e cheio de focos que se interseccionam e uma rede relacionada de significados. Quanto mais rico o currículo, mais haverá pontos de intersecção, conexões construídas, e mais profundo será seu significado.

Essa ideia de rede mostra o quão complexa e séria é a análise da busca do conceito de currículo, pois os processos acontecem de forma concomitante. Não é possível defini-lo para somente depois pensar sua relação com a prática escolar, pois as ações são imbricadas.

Os currículos sofrem mudanças no decorrer da história, a partir de questionamentos e reflexões e, para garantir cada vez mais a aprendizagem de todos e de cada um dos estudantes, com o currículo de Matemática não é diferente. Há uma busca contínua de formas mais significativas de se trabalhar Matemática em sala de aula, com escolhas metodológicas mais acertadas e interessantes. É possível verificar, no entanto, que reformas curriculares não garantem prontamente uma mudança efetiva na prática docente. Elas são mais lentas e complexas.

Desde a década de 50, as reformas na área de Matemática são pauta de discussões dos pesquisadores. Foi no final desta década que teve início o Movimento da Matemática Moderna, que objetivava aproximar o ensino escolar da ciência e da técnica, com uma política de formação a serviço da modernização econômica. Essa reforma provocou mudanças curriculares em muitos países, como Inglaterra, Estados Unidos, França, Brasil, Nigéria, entre outros. Os conceitos fundamentais da Matemática Moderna consideravam-na como viva, profunda e constituinte de uma linguagem universal.

Para Pires (2008), no Brasil, a Matemática Moderna surgiu para substituir a "velha Matemática", sendo veiculada, principalmente, por meio dos livros didáticos. A autora destaca que não houve uma discussão dos propósitos nem uma preparação dos educadores para essa mudança. 
O professor de matemática Oswaldo Sangiorgi ${ }^{1}$ foi um dos responsáveis por divulgar o Movimento da Matemática Moderna no país. O Grupo de Estudos do Ensino da Matemática (GEEM)² também se envolveu na disseminação das ideias desse movimento na década de 60.

No entanto, a organização curricular da Matemática Moderna de forma quase sempre linear começou a incomodar alguns pesquisadores que buscavam um currículo mais rico e contextualizado cultural e socialmente. Além da dificuldade de formação de professores para atuar com as ideias do Movimento da Matemática Moderna, isso deu início ao declínio desse movimento a partir da década de 80 na predominância das discussões realizadas pelas Secretarias Estaduais e Municipais de Educação.

Esse período, marcado pela abertura democrática no Brasil, inspirou uma nova caracterização do currículo, por meio da implementação de propostas curriculares para os ensinos de $1^{\circ}$ e $2^{\circ}$ graus.

Nessa proposta foi conferida à Matemática uma dupla função no currículo, defendendo-se que "ela é necessária em atividades práticas que envolvem aspectos quantitativos da realidade, como as que lidam com grandezas, contagens, medidas, técnicas de cálculo" e que "ela desenvolve o raciocínio lógico, a capacidade de abstrair, generalizar, transcender o que é imediatamente sensível". Uma das preocupações explicitadas era a de apresentar o conteúdo, em diferentes níveis de abordagem, em que se procura respeitar a integração dos temas a serem trabalhados, bem como seu desenvolvimento "em espiral", conforme preconiza Jerome Bruner. (PIRES, 2000, p. 50-51)

Assim, as reformas curriculares foram reelaboradas com aspectos bastante similares aos das propostas das Secretarias Estaduais e Municipais do Estado e da Cidade São Paulo por todo país. Esse movimento de reorganização curricular teve a interdisciplinaridade como organizadora da ação pedagógica da escola, buscando superar a fragmentação do conhecimento.

O uso de temas geradores foi escolhido por permitir o estabelecimento de uma relação entre o currículo da escola e a realidade de seu entorno. Essa perspectiva permitia o levantamento de um problema da comunidade local e a busca de soluções para o mesmo.

\footnotetext{
${ }^{1}$ Professor da disciplina Matemática e autor de livros didáticos da época do Movimento da Matemática Moderna (MMM) no Brasil e um dos pioneiros na divulgação do MMM no Brasil. Ganhou o prêmio Jabuti na categoria "Ciências Exatas" em 1964 pelo livro "Matemática Curso Moderno".

${ }^{2}$ Fundado em 1961, com sede na Universidade Mackenzie, o Grupo de Estudos do Ensino da Matemática (GEEM), sob presidência do professor Sangiorgi, e tendo como colaborador o docente George Springer que havia sido seu professor no Curso de Verão na Universidade de Kansas e seu colega de trabalho no curso de Especialização na Universidade Mackenzie. A constituição e atuação deste Grupo foram de extrema importância para a implantação e divulgação do Movimento da Matemática Moderna no Brasil, por meio de cursos similares aos que o professor Sangiorgi participou na Universidade de Kansas e organizou e ministrou na Universidade Mackenzie. Desde sua constituição, o GEEM contou com o apoio da Secretaria do Estado de São Paulo, garantindo, assim, viabilidade financeira para suas atividades, inclusive oferecendo bolsas de estudos aos docentes e outros Grupos com a mesma finalidade.
} 
Em $1995^{3}$, a reflexão permanente sobre o currículo desencadeou a publicação dos Parâmetros Curriculares Nacionais (PCN) para o Ensino Fundamental pelo Ministério da Educação, que, após discussões com educadores de diferentes níveis do sistema educativo, indicaram diretrizes curriculares comuns para o Ensino Fundamental no Brasil. Pires (2008, p. 26) destaca que os PCN,

[...] explicitaram o papel da Matemática pela proposição de objetivos que evidenciam a importância de o aluno valorizá-la como instrumental para compreender o mundo a sua volta e de vê-la como área do conhecimento que estimula o interesse, a curiosidade, o espírito de investigação e o desenvolvimento da capacidade de resolver problemas.

Os PCN trouxeram a resolução de problemas como ponto de partida para as atividades matemáticas e a importância do trabalho integrado entre os blocos de conteúdos e as demais áreas do conhecimento. Outro aspecto que merece destaque é que os PCN ressaltaram a necessidade de explorar os conteúdos nas dimensões conceituais, procedimentais e atitudinais.

A relevância social dos conteúdos adotados e a ação efetiva dos estudantes frente ao conhecimento são reiteradas nessa proposta a todo o momento. Isso demonstra a preocupação constante com a superação de concepções que organizavam o currículo de maneira linear e sem uma efetiva preocupação com a (re)construção de conhecimentos pelos estudantes ao considerar todo capital cultural presente.

Houve um avanço considerável na organização curricular da Matemática a partir de debates e reflexões, o que não significa, no entanto, que haja no país uma tradição na comunidade de educadores de debates e pesquisas constantes acerca do currículo e sua efetivação enquanto prática qualificada.

O quadro 1, organizado por Pires (2008), resume as principais características presentes em documentos curriculares, nos diferentes movimentos de reforma. Ele é importante por permitir uma visualização elucidativa das diferenças entre os movimentos de reestruturação curricular em seu contexto histórico. As discussões culturais apresentadas no quadro trazem ao debate aspectos que surgem para responder às novas demandas educacionais.

Quadro 1- Resumo das principais referências na construção do currículo de Matemática

\begin{tabular}{|c|c|c|c|}
\hline & Influência do MMM & Crítica ao MMM & $\begin{array}{c}\text { Consolidação de novas } \\
\text { ideias }\end{array}$ \\
\cline { 2 - 4 } & Anos 1950 - 1960 & Anos 1970 - 1980 & Anos 1990 - 2000 \\
\hline $\begin{array}{c}\text { Epistemologia } \\
\text { Subjacente }\end{array}$ & $\begin{array}{c}\text { Foco no problema lógico } \\
\text { e na estruturação do } \\
\text { conhecimento a partir das } \\
\text { estruturas matemáticas }\end{array}$ & $\begin{array}{c}\text { Foco nas experimentações e } \\
\text { nas explicações dos porquês }\end{array}$ & $\begin{array}{c}\text { Foco no construtivismo e } \\
\text { na construção de } \\
\text { conhecimentos pelos } \\
\text { alunos }\end{array}$ \\
\hline
\end{tabular}

\footnotetext{
${ }^{3}$ Os Parâmetros Curriculares Nacionais (PCN) para o primeiro e segundo ciclos do ensino fundamental foram os primeiros a ser definidos pelo Ministério da Educação e a vir a público no final de 1995, quando uma versão preliminar foi encaminhada para consulta e avaliação a professores e acadêmicos de várias instituições do país.
} 


\begin{tabular}{|c|c|c|c|}
\hline $\begin{array}{c}\text { Didática } \\
\text { Subjacente }\end{array}$ & Foco no ensino & Foco na aprendizagem & $\begin{array}{c}\text { Foco na aprendizagem e } \\
\text { no saber }\end{array}$ \\
\hline $\begin{array}{c}\text { Modelos } \\
\text { Pedagógicos } \\
\text { Dominantes }\end{array}$ & Teoricismo e Tecnicismo & $\begin{array}{c}\text { Modernismo e } \\
\text { Procedimentalismo }\end{array}$ & $\begin{array}{c}\text { Psicologismo e } \\
\text { Modelização }\end{array}$ \\
\hline Influências & Grupo Bourbaki Piaget & $\begin{array}{c}\text { Didática da Matemática } \\
\text { Francesa } \\
\text { (Chevallard, Brousseau, } \\
\text { Vergaud e outros) }\end{array}$ & $\begin{array}{c}\text { Etnomatemática, } \\
\text { Modelagem }\end{array}$ \\
\hline $\begin{array}{c}\text { Seleção de } \\
\text { Conteúdos }\end{array}$ & $\begin{array}{c}\text { Em função da estrutura da } \\
\text { ideias centrais }\end{array}$ & $\begin{array}{c}\text { Relevância social e formação } \\
\text { matemática do aluno }\end{array}$ & $\begin{array}{c}\text { Relação com constituição } \\
\text { de competências e } \\
\text { habilidades }\end{array}$ \\
\hline $\begin{array}{c}\text { Organização de } \\
\text { Conteúdos }\end{array}$ & Organização Linear & $\begin{array}{c}\text { Início da quebra da } \\
\text { linearidade }\end{array}$ & $\begin{array}{c}\text { Contextualização e } \\
\text { interdisciplinaridade }\end{array}$ \\
\hline $\begin{array}{c}\text { Modalidades } \\
\text { organizativas }\end{array}$ & Lições teóricas & Atividades e experiências & $\begin{array}{c}\text { Projetos e sequências } \\
\text { didáticas }\end{array}$ \\
\hline $\begin{array}{c}\text { Relação } \\
\text { Professor/Aluno }\end{array}$ & Centrada no professor & Centrada no aluno & $\begin{array}{c}\text { Centrada na relação } \\
\text { professor aluno }\end{array}$ \\
\hline
\end{tabular}

Fonte: Pires (2008, p. 37)

\section{Diversidade, Cultura, Currículo e Educação Matemática}

A escola é o espaço da diversidade. Espaço carregado de diferenças sociais, étnicas, raciais, de gênero, de espaços de origem, de saberes, isto é, de cultura. A pluralidade cultural, tão expressa socialmente, é parte do cotidiano escolar em seus confrontos e conflitos e, por esse motivo, torna-se central nas discussões relacionadas ao currículo. Para Moreira e Candau (2007, p. 27),

[...] a palavra "culturas" (no plural) corresponde aos diversos modos de vida, valores e significados compartilhados por diferentes grupos (nações, classes sociais, grupos étnicos, culturas regionais, geracionais, de gênero etc.) e períodos históricos. Trata-se de uma visão antropológica de cultura, em que se enfatizam os significados que os grupos compartilham, ou seja, os conteúdos culturais. Cultura identifica-se, assim, com a forma geral de vida de um dado grupo social, com as representações da realidade e as visões de mundo adotadas por esse grupo. [...] Concebe-se, assim, a cultura como prática social, não como coisa (artes) ou estado de ser (civilização).

E, ao analisar a relação entre currículo e cultura, complementam:

Nesse enfoque, coisas e eventos do mundo natural existem, mas não apresentam sentidos intrínsecos: os significados são atribuídos a partir da linguagem. Quando um grupo compartilha uma cultura, compartilha um conjunto de significados, construídos, ensinados e aprendidos nas práticas de utilização da linguagem. A palavra cultura implica, portanto, o conjunto de práticas por meio das quais significados são produzidos e compartilhados em um grupo. São os arranjos e as relações envolvidas em um evento que passam, dominantemente, a despertar a atenção dos que analisam a cultura com base nessa quinta perspectiva, passível de ser resumida na ideia de que cultura representa um conjunto de práticas significantes. Não será pertinente considerarmos também o currículo como um 
conjunto de práticas em que significados são construídos, disputados, rejeitados, compartilhados? (MOREIRA; CANDAU, 2007, p. 27)

Hall (1997) aponta que essa centralidade da cultura se dá pelo fato de que ela tem relação com tudo o que acontece em nossa vida, significando-a, e não por supostamente ser superior a outras dimensões (social, política, econômica, educacional), mas porque atravessa as diversas práticas sociais.

A centralidade e a importância da cultura no mundo contemporâneo atinge diretamente o currículo e motiva-nos a repensá-lo, considerando essa pluralidade. Um currículo orientado culturalmente é o que concebe o conhecimento de diferentes perspectivas (diversidade) com diversas abordagens e interpretações, colocando em xeque perspectivas socialmente mais valorizadas e que precisam ser reescritas.

Para reescrevê-las, será necessário ouvir vozes que foram silenciadas por toda a história e expor as relações de poder que se estabeleceram historicamente. Assim, romper com práticas homogeneizadoras faz-se necessário para que a escola possa se tornar espaço de interação de identidades culturais distintas. Todas essas questões convergem para a iminente necessidade da organização de um currículo multiculturalmente estruturado e que possa apontar caminhos e nortear as construções coletivas para enfrentar os desafios trazidos por essa diversidade cultural.

Nesse ponto, retomamos a discussão sobre as escolhas que compõem o currículo e o desafio imenso que está posto aos educadores: como garantir que todas as diferenças culturais e étnicas estejam representadas no currículo? Quais vozes estarão presentes e quais ainda continuam silenciadas? Como serão trabalhadas as diferentes identidades e as relações de poder?

Uma perspectiva que ajuda a responder algumas dessas questões é a intercultural que, segundo Candau (2011, p. 1),

[...] quer promover uma educação para o reconhecimento do "outro", para o diálogo entre os diferentes grupos sociais e culturais. Uma educação para a negociação cultural, que enfrenta os conflitos provocados pela assimetria de poder entre os diferentes grupos socioculturais nas nossas sociedades e é capaz e favorecer a construção de um projeto comum, pelo qual as diferenças sejam dialeticamente incluídas.

Portanto, está presente aqui o desafio para a escola, em torno dessa discussão que ainda caminha a passos lentos e que merece, por sua complexidade, mais estudos, análises e construções por parte de todos os envolvidos com a prática pedagógica. D’Ambrósio (1999, p. 52) estabelece a etnomatemática como campo de pesquisa que pretende compreender a forma como o conhecimento é gerado e difundido social e intelectualmente. Para o autor,

[...] cada cultura desenvolveu sua própria maneira, estilos e técnicas de fazer, e respostas à procura por explicações, entendimentos e aprendizagem. Estes são os 
sistemas de conhecimento. Todos esses sistemas usam inferência, quantificação, comparação, classificação, representação, medida. É claro que a matemática ocidental é um desses sistemas de conhecimento, como nos mostra uma visão ampla de sua história. Mas outras culturas desenvolveram, também, outros sistemas de conhecimento com os mesmos objetivos. Isto é, são outras 'matemáticas', usando diferentes maneiras de inferir, quantificar, comparar, classificar, representar, medir. Todos esses sistemas de conhecimento poderiam ser chamados etnomatemáticas. Eles são as 'matemáticas' de diferentes ambientes naturais e culturais, todos motivados pela busca por sobrevivência e transcendência.

De acordo com D’Ambrósio (2001, p.76), a etnomatemática relaciona-se com a matemática praticada por diferentes grupos culturais "que se identificam por objetos e tradições comuns aos grupos”. A etnomatemática possibilita a relação da matemática escolar com os conhecimentos que fazem parte da sociedade (SANTOS, 2004). Este autor pondera sobre sua presença na escola.

A etnomatemática não como um método de ensino em si, mas sim como detentora de relações inclusivas entre professores e alunos e das diversas formas de conhecer presentes em contextos culturais/socioculturais diferentes. [...] Dessa forma, entendemos o 'diálogo', a 'contextualização' e a 'comparação', como pilares que alicerçam a pedagogia etnomatemática podendo, ainda, ser entendidos como posturas necessárias ao professor dentro dessa pedagogia. (SANTOS, 2004, p. 211)

O cotidiano apresenta os saberes que foram historicamente construídos pelas diferentes culturas. Por meio da etnomatemática, é possível compreender - porque este é seu objeto de estudo - como o fazer matemático constituiu-se ao longo da história da humanidade,

[...] contextualizado em diferentes grupos de interesse, comunidades, povos e nações; e sua principal razão é o resultado de uma preocupação com as tentativas de propor uma epistemologia, e, como tal, uma explicação final da etnomatemática. Ao insistir na denominação 'programa etnomatemática', D'Ambrósio procura evidenciar que não se trata de propor uma outra epistemologia, mas de entender a aventura da espécie humana na busca do conhecimento e na adoção de comportamentos (GODOY, 2015, p. 162).

É evidente na fala de D’Ambrósio (1996, P. 111) a necessidade de pautar a ação em um currículo, no qual as questões multiculturais estejam presentes, porque é evidente que

[...] o reconhecimento da subordinação dos conteúdos programáticos à diversidade cultural que impera num país como o Brasil. Igualmente o reconhecimento de uma variedade de estilos de aprendizagem, implícito no apelo ao desenvolvimento de novas metodologias. Essencialmente, essas considerações determinam uma enorme flexibilidade tanto na seleção de conteúdos quanto na metodologia.

Em sua dimensão educacional, a etnomatemática "incorpora valores da humanidade para a condução da vida cotidiana do indivíduo, ponderando todos os aspectos inerentes: emocional, social, cultural, afetivo, político e econômico" (GODOY, 2015, p. 165). Além disso, de acordo com o autor, é possível afirmar que "a etnomatemática trouxe um caminho para uma educação renovada, 
capaz de preparar gerações futuras para construir uma sociedade mais justa e igualitária" (GODOY, 2015, p. 165).

Borba (2010) aponta que os estudos produzidos que se relacionam com a etnomatemática na década de 80 - foram decisivos para o surgimento da educação matemática crítica, que tem como um de seus precursores Ole Skovsmose, e que, segundo Godoy (2015, P. 180), esse "trabalho nos ajudará a entender melhor como a matemática escolar pode tanto se aproximar de uma educação mais democrática, igualitária e justa quanto contribuir para ela”.

A ideia mais geral e unificadora é: para que a educação, tanto como prática quanto como pesquisa, seja crítica, ela deve discutir condições básicas para a obtenção do conhecimento, deve estar a par dos problemas sociais, das desigualdades, da supressão etc., e deve tentar fazer da educação uma força social progressivamente ativa. Uma educação crítica não pode ser um simples prolongamento da relação social existente. Não pode ser um acessório das desigualdades que prevalecem na sociedade. Para ser crítica, a educação deve reagir às contradições sociais (SKOVSMOSE, 2013, p. 101).

A reflexão do papel da matemática na sociedade e do posicionamento crítico frente às situações cotidianas, por meio da formação matemática dos estudantes, são alguns dos objetivos da educação matemática crítica. Ela pode tornar submissas ou empoderar as pessoas. À escola - e a seus professores - cabe cuidar para diminuir a exclusão dos menos privilegiados e fazer da educação matemática instrumento de poder para a transformação da sociedade.

Para Silva (2009), a educação crítica pode estabelecer uma nova perspectiva do processo de ensino e de aprendizagem e das relações e papéis de professores e estudantes nessa ação, possibilitando reflexões específicas quando tratarmos do currículo.

Este posicionamento que diferencia o ensino da matemática, tornando-o muito mais significativo, em que situações do cotidiano ou mesmo de outras áreas do conhecimento são utilizadas, passa pela possibilidade de modelar situações externas ao contexto escolar no ensino. A modelagem matemática, trabalhada tanto na perspectiva da matemática aplicada quanto na educação matemática, tem como premissa a construção e resolução de problemas envolvendo situações externas a disciplina que articulam a matemática escolar com situações cotidianas.

A modelagem matemática apresenta relação com a resolução de problemas, pois "é um ambiente de aprendizagem no qual os estudantes são convidados a indagar e/ou investigar, por meio da matemática, situações com referência na realidade" (BARBOSA, 2009, p. 19). Assim, apresenta forte relação com a etnomatemática e com a educação matemática crítica na medida em que

as ideias principais que orientam o projeto etnomatemático são: 1) é possível identificar uma competência matemática escondida, mas fundamental, em todos os diferentes ambientes culturais; essa competência se manifesta de diferentes formas, por exemplo, em habilidades como as dos artesãos; 2) essa competência matemática escondida poderia se tornar explícita como etnomatemática; 3) é 
possível desenvolver uma educação matemática baseada na competência etnomatemática preestabelecida. (SKOVSMOSE, 2013, p. 49)

Como é possível perceber, as reflexões culminam em construções de novas ideias e significações do currículo de Matemática. Essas reflexões têm como principal espaço de construção a escola e os(as) professores(as) nela inseridos(as). Esse movimento para a mudança é fundamental.

No entanto, romper com a organização linear requer repensar a função da escola como um todo, levando em consideração a sociedade na qual está inserida, sua concepção de conhecimento, aprendizagem e autonomia intelectual. É nesse viés que "a ideia de rede, utilizada com o propósito de articular disciplinas no currículo, traz novas possibilidades para projetos interdisciplinares" (PIRES, 2000, p. 144). Esta autora afirma ainda que:

o princípio da topologia das redes mostra que nas redes curriculares tudo funciona por proximidade, por vizinhança. Nelas, o curso dos acontecimentos é uma questão de topologia, de caminhos. Tudo que se desloca deve utilizar-se da rede tal como ela se encontra, ou então será obrigado a modifica-la. Essa ideia pode trazer contribuições no sentido de eliminar a artificialidade de algumas propostas interdisciplinares, que na tentativa de privilegiar determinados temas, colocam-nos no centro das atenções e, de forma artificial, criam conexões para agrupar, em torno dele, assuntos de todas as disciplinas, fazendo com que a interdisciplinaridade pareça mais uma camisa-de-força do que uma forma atraente de organização curricular. (PIRES, 2000, p. 145)

A proposta trazida por Pires (2000) evidencia a possibilidade da organização curricular da Matemática por meio do enredamento de projetos desta área em projetos mais amplos da escola, em uma visão de totalidade, inserindo todo o trabalho em uma grande teia educacional.

No campo cognitivo, a ideia de rede comparece cada vez que se pretende demonstrar que a compreensão do tema é construída por meio de múltiplas relações, que podem ser estabelecidas entre ele e outros temas, estejam ou não as fontes de relação no âmbito de uma dada disciplina. Nesse contexto, o conhecimento é apresentado como uma rede cujos pontos vão se construindo em várias direções, em vários sentidos, cuja formação se altera e se reestrutura praticamente a cada vez que um "ponto" é incorporado a ela; é um sistema, enfim, que passa por momentos de caos e de alguma estabilidade (PIRES, 2000, p. 117).

A reestruturação curricular serve a esse modelo à medida que permite a construção de conhecimento de maneira bem mais significativa, diferentemente de uma concepção linear e acumulativa. É nessa mesma linha de pensamento que Bishop (1999) apresenta uma proposição sobre o currículo denominada Enculturação Matemática. Para o autor, as atividades desenvolvidas em sala de aula devem ser adequadas ao nível dos estudantes e trazer problemas em contextos significativos, baseados no entorno físico e social. Segundo Bishop (1999, p. 222), organizar o currículo com esses princípios empodera o professor, que deve ser também um enculturador, e transforma a educação, pois 
[...] outro papel importante dos educadores matemáticos é propiciar um contexto social, para refletir sobre a enculturação Matemática e estimular a crítica, a pesquisa, a análise e o desenvolvimento. $\mathrm{O}$ grande crescimento das pesquisas na educação matemática nos últimos anos pode ser atribuído ao crescente reconhecimento da importância dessa atitude crítica e o desejo de buscar melhores formas de educar nossos filhos.

Assim, convergindo com as reflexões apontadas por Bishop (1999), estão as contribuições de Rico (1998, p. 21) sobre a importância da Educação Matemática.

Os objetivos para atender e justificar a presença da matemática na educação respondem a três tipos de argumentos. Em primeiro lugar, a matemática é considerada como tendo um valor educativo alto, pois ela desenvolve capacidades de raciocínio lógico, simbolismo, abstração, rigor e precisão que caracterizam o pensamento formal. Em segundo lugar, a matemática tem interesse em sua utilidade. Matemática aparece em quase todas as formas de expressão humana, para codificar informações e obter representação e é um ambiente social e natural, poderoso o suficiente para novas ações. [...] Em terceiro lugar, a matemática fornece, juntamente com a linguagem, um dos tópicos condutores da formação intelectual dos estudantes. Matemática exige um desenvolvimento contínuo e progressivo que, por sua vez, nos permite apreciar o desenvolvimento feito pelo aluno.

Para que esse contexto ocorra, é necessário que o currículo ofereça aos professores propostas concretas para o entendimento do conhecimento e da interpretação da mensagem (RICO, 1998). Além disso, ao colocar em prática o que há no currículo, é preciso demonstrar, em sala de aula, a utilidade dos conteúdos apreendidos. Dessa forma, será possível estabelecer dimensões prioritárias na organização curricular, que são culturais, sociais, formativas ou educativas e políticas (RICO, 1998). Ao trabalhar com essas quatro dimensões no ensino, permite-se, finalmente, obter a estruturação da Educação Matemática e seus fins, de maneira a poder elencar os programas de inovação curricular, definindo as metas distintas para cada sociedade, comunidade, ou país.

De acordo com Rico (1998), os tipos de reflexão diferentes são apresentados quando são colocados em destaque o ponto de vista teórico, o que dificulta, para o professor em sala de aula, a utilização do currículo como um plano de ação. Logo, quando o currículo é considerado como “planificação" para a administração educativa, o sistema de atuação só poderá ser o educativo.

O quadro 2 apresenta as diferentes aproximações no estudo do currículo e mostra as quatro ordens de dimensões permanentes que podem ser utilizadas como base para a estruturação de um currículo. Assim, de acordo com Rico (1998), quando se utiliza o currículo como objeto de estudo, adentra-se a um nível de reflexão acadêmico; quando o currículo é utilizado para fins gerais da educação, tem-se um nível de reflexão denominado de teleológico.

Nos últimos trinta anos, os estudos sobre o currículo de Matemática tem como foco a busca por componentes que possam permitir a estrutura adequada do sistema curricular. Para Rico (1997), 
dependendo de qual nível de reflexão é trabalhado, diferentes dimensões podem ser encontradas. Esses estudos também apresentam teorias sobre os fins da Educação Matemática.

Quadro 2 - Níveis e dimensões no estudo do currículo

\begin{tabular}{|c|c|c|c|c|}
\hline $\begin{array}{c}\text { Componentes por } \\
\text { Nível }\end{array}$ & $\begin{array}{c}\text { Dimensão } \\
\text { Cultural }\end{array}$ & $\begin{array}{c}\text { Dimensão } \\
\text { Cognitiva }\end{array}$ & $\begin{array}{c}\text { Dimensão } \\
\text { Formativa }\end{array}$ & $\begin{array}{c}\text { Dimensão } \\
\text { Social }\end{array}$ \\
\hline $\begin{array}{c}\text { Planificação para } \\
\text { professores }\end{array}$ & Conteúdos & Objetos & Metodologia & Avaliação \\
\hline Sistema Educativo & Conhecimentos & Alunos & Professor & Aula \\
\hline $\begin{array}{c}\text { Disciplinas } \\
\text { Acadêmicas }\end{array}$ & $\begin{array}{c}\text { Epistemologia e } \\
\text { História da } \\
\text { Matemática }\end{array}$ & $\begin{array}{c}\text { Teorias da } \\
\text { aprendizagem }\end{array}$ & Aluno & Sociologia \\
\hline $\begin{array}{c}\text { Teleológico ou de } \\
\text { finalidades }\end{array}$ & Fins Culturais & Fins formativos & Fins políticos & Fins Sociais \\
\hline
\end{tabular}

Fonte: Rico (1998, p. 24).

É possível perceber, então, que o debate sobre os fins da Educação Matemática torna-se uma questão muito importante para a elaboração do currículo de Matemática em um sistema educativo, principalmente, quando pensamos em educação obrigatória. Essas preocupações devem envolver os contextos políticos, culturais, sociais e educativos.

A ideia trazida por Rico (1998) aponta que, juntamente com autores como Bishop (1999) e Pires (2000), o ensino da Matemática precisa ser mais significativo para o estudante e qualificado como parte integrante de uma cultura socialmente construída. Ambos autores retomam a importância do professor na implementação do currículo. É esse profissional que, por meio de escolhas metodológicas e didáticas, significa os conteúdos e os qualifica no processo de ensino e de aprendizagem. Rico (1998) aponta que não basta dominar os conteúdos técnicos da matemática: ensinar requer conhecimento profundo sobre o currículo, conhecimento didático e interdisciplinar. Segundo Pires (2008, p. 40),

[...] numa espécie de "convivência eterna" de currículos prescritivos (os dos documentos oficiais) e os currículos reais (os da sala de aula, que os professores realizam). Desse modo, um fenômeno comum a diferentes níveis do sistema de ensino (federal, estadual, municipal) é a introdução, em determinados períodos, de mudanças curriculares que não têm o apoio de experiências concretas anteriores nem o envolvimento dos professores, protagonistas de sua implementação.

É importante considerar que a coerência entre o currículo prescrito e o currículo realizado poderia ocorrer se a proximidade entre educadores e pesquisadores da área de currículo acontecesse efetivamente. Há uma infinidade de caminhos que podem estreitar essa reflexão conjunta que certamente qualificaria as práticas escolares. De acordo com Rico (1995), os professores precisam 
assumir-se como profissionais críticos e renovados, que, intimamente implicados na reflexão sobre o currículo, garantiriam uma aprendizagem mais significativa, já que conheceriam profundamente o que produziram enquanto proposta curricular. Assim, um currículo de educação básica deve se propor a responder aos seguintes questionamentos: "O que é e em que consiste o conhecimento? O que é aprendizagem? O que é ensino? O que é e em que consiste o conhecimento útil?” (RICO, 1997, p. 11).

Portanto, o currículo deve oferecer propostas palpáveis sobre as formas de entender e interpretar a aprendizagem e de colocar em prática o ensino, valorizando o uso e o domínio dos conteúdos apreendidos (RICO, 1997). De acordo com Pires (2004, p. 59),

[...] a perspectiva de construção de currículos de Matemática mais ricos, contextualizados culturalmente e socialmente, com grandes possibilidades de estabelecimento de relações intra e extra-matemática, com o rigor e a conceituação matemáticos apropriados, acessíveis aos estudantes, evidenciando o poder explicativo da Matemática, com estruturas mais criativas que a tradicional organização linear [...] deve ser uma meta a ser perseguida pelos educadores matemáticos em suas pesquisas e em suas práticas.

Essas discussões e reflexões são fundamentais e podem servir como suportes para apontar as potencialidades e os limites do currículo como caminho para a conquista de uma educação a serviço da justiça social.

\section{Considerações finais}

O presente artigo apresentou um panorama sobre o processo de constituição do currículo matemático escolar, abordando a reorganização curricular em diferentes momentos, bem como a influência da diversidade e da cultura sobre a elaboração de currículos, trazendo a demanda de novos enfoques como interdisciplinaridade, temas geradores e projetos, para pensar sobre os processos de ensino e de aprendizagem da Matemática.

A Educação Matemática traz para o centro das discussões o ensino significativo e a ideia de rede (contrapondo-se ao ensino linear dos conteúdos). Com isso, passam a fazer parte das discussões questões relacionadas ao multiculturalismo, etnomatemática, educação matemática crítica e modelagem matemática, entre outras tendências, que ampliam os espaços e tempos do processo de ensino e de aprendizagem.

Atualmente, temos a proposta da Base Nacional Comum Curricular (BNCC) que propõe mudanças no ensino da Matemática. Uma das principais mudanças, e talvez a mais benéfica, é um olhar multicultural para o currículo. Assim, relacionar as disciplinas, dando ao estudante a oportunidade de perceber o sentido dos conteúdos, fazendo uso social do mesmo e acessando plenamente sua cidadania, possibilitará que à Matemática deixe de ser considerada tão abstrata e, 
portanto, favorecerá seu aprendizado em sala de aula, estando ao alcance de todos, estudantes e professores, como sugere a BNCC.

Para que isso ocorra, é necessário que o professor veja a sala de aula como um espaço de troca, reflexão e aprendizagem, de valorização de toda a bagagem social e cultural do estudante, de seus conhecimentos prévios, de suas experiências com a família e com a comunidade. Assim, poderão ser apresentadas em sala de aula situações relacionadas à vida real, que serão utilizadas no processo de ensino e de aprendizagem, que não estão distantes dos estudantes, possibilitando a compreensão dos conteúdos de modo mais significativo.

Podemos perceber que ainda há vivências do ensino tradicional em nossa sociedade. Esse contexto tem dificultado a inclusão de currículos mais alinhados com as demandas educacionais atuais da sociedade. Porém, sabemos que o processo de mudança é demorado; e o importante é que já foram dados passos importantes para a alteração dessa realidade no ensino brasileiro. A BNCC pode contribuir para essa mudança fundamental e para as propostas significativas elaboradas e planejadas pelos professores.

Cabe ressaltar, também, que o currículo não deve ser entendido como um produto ou um objeto estático em que há uma delimitação no que pode planejar e, em seguida, implantar; ele deve apresentar a cultura real da sociedade, buscando processos que decidam sobre o que será feito com relação ao ensino.

\section{Referências}

BRASIL. Ministério da Educação. Secretaria de Educação Fundamental. Parâmetros Curriculares Nacionais: Matemática. Brasília: MEC/SEF, 1998.

BARBOSA, Jonei Cerqueira. Integrando Modelagem Matemática nas práticas pedagógicas. Educação Matemática em Revista, São Paulo, v. 14, n. 26, p. 17-25, mar. 2009.

BISHOP, Alan. J. Enculturación matemática: la educación matemática desde una perspectiva cultural. Traducción de Genis Sánchez Barberán. Barcelona: Paidós, 1999.

BORBA, Marcelo de Carvalho. Prefácio. In: SKOVSMOSE, Ole. Educação Matemática Crítica: a questão da democracia. Tradução de Abigail Lins e Jussara de Loiola Araújo. 5. ed. Campinas: Papirus, 2010.

CANDAU, Vera Maria. Multiculturalismo e Educação: desafios para a prática pedagógica. In: MOREIRA, Antônio Flávio Barbosa; CANDAU, Vera Maria. Multiculturalismo: diferenças culturais e práticas pedagógicas. 8 ed. Petrópolis: Vozes, 2011. p. 13-37.

D’AMBRÓSIO, Ubiratan. História da Matemática e Educação. Cadernos CEDES 40: História e Educação Matemática. Campinas: Papirus, 1996. p.7-17.

D’AMBRÓSIO, Ubiratan. A História da Matemática: questões historiográficas e políticas e reflexos na Educação Matemática. In: BICUDO, Maria Aparecida Viggiani. (Org.). Pesquisa em Educação Matemática: concepções e perspectivas. São Paulo: EdUNESP, 1999. p. 97-115. 
D’AMBRÓSIO, Ubiratan. Educação para uma sociedade em transição. 2. ed. Campinas: Papirus, 2001.

DOLL JR., William E. Currículo: uma perspectiva pós-moderna. Tradução de Maria Adriana Veríssimo Veronese. Porto Alegre: Artes Médicas, 1997.

GODOY, Elenilton Vieira. Currículo, cultura e Educação Matemática: uma aproximação possível? Campinas: Papirus, 2015.

HALL, Stuart. A centralidade da cultura: notas sobre as revoluções culturais do nosso tempo. Educação \& Realidade, Porto Alegre, v. 22, n. 2, p. 15-46, jul./dez. 1997.

MOREIRA, Antônio Flávio Barbosa; CANDAU, Vera Maria. Indagações sobre o currículo: currículo, conhecimento e cultura. Brasília: Ministério da Educação, 2007, p. 5-21.

PIRES, Célia Maria Carolino. Currículos de matemática: da organização linear à ideia de rede. São Paulo: FTD, 2000.

PIRES, Célia Maria Carolino. Formulações basilares e reflexões sobre a inserção da Matemática no currículo, visando a superação do binômio máquina e produtividade. Educação Matemática Pesquisa, São Paulo, v. 6, n. 2, p. 29-61, 2004.

PIRES, Célia Maria Carolino. Educação Matemática e sua Influência no Processo de Organização e Desenvolvimento Curricular no Brasil. Boletim de Educação Matemática - Bolema, Rio Claro, v. 21, n. 29, p. 13-42, 2008.

RICO, Luis. Consideraciones sobre el currículo escolar de Matemáticas. EMA, v. 1, n. 1, p. 4-24. 1995.

RICO, Luis. Consideraciones sobre el currículo de matemáticas para educación secundaria. In:

RICO, Luis (Org.). La educación matemática en la enseñanza secundaria. Madrid: ICEUniversidad de Barcelona-Horsori, 1997. p. 15-38.

RICO, Luis. Concepto de currículo desde la educación matemática. Revista de Estudios del Currículum, v. 1, n. 4, p. 7-42. 1998.

SACRISTÁN, Jose. Gimeno. O currículo: uma reflexão sobre a prática. 3. ed. Tradução: Ernani F. da Fonseca Rosa. Porto Alegre: Artmed, 2000.

SANTOS, Benerval Pinheiro. Etnomatemática e suas possibilidades pedagógicas: algumas indicações. In: RIBEIRO, José Pedro Machado; DOMITE, Maria do Carmo Santos; FERREIRA, Rogerio. Etnomatemática: papel, valor e significado. São Paulo: Zouk, 2004. p. 203-218.

SILVA, Marcio Antonio. Currículo por competências ou currículo crítico? Uma análise da Proposta Curricular do Estado de São Paulo. Boletim GEPEM, n. 55, p. 113-132. 2009.

SKOVSMOSE, Ole. Educação Matemática Crítica: a questão da democracia. Tradução de Abigail Lins e Jussara de Loiola Araújo. 6. ed. Campinas: Papirus, 2013.

Submetido em março de 2016

Aprovado em maio de 2016 